\title{
Improving academic outcomes: does participating in online discussion forums payoff?
}

\section{Charles Carceller*}

School of Education,

Faculty of Social Sciences,

University of Wollongong,

Wollongong, NSW, 2522, Australia

Email: charles_carceller@uow.edu.au

*Corresponding author

\section{Shane Dawson}

Learning and Teaching Unit,

University of South Australia,

GPO Box 2471, Adelaide,

South Australia, 5001, Australia

Email: Shane.Dawson@unisa.edu.au

\section{Lori Lockyer}

School of Education,

Faculty of Human Sciences,

Macquarie University,

Balaclava Road, North Ryde, NSW, 2109, Australia

Email: lori.lockyer@mq.edu.au

\begin{abstract}
This paper reports on a study investigating the potential relationship between a student's discussion forum activity and their academic performance. The study also examined the influence of the delivery method (i.e. blended or fully online) on the impact that forum participation may have on a student's final mark. To address these aims, student forum participation data and teaching delivery method were extracted from the universities Learning Management System (LMS). The analysis identified that students who actively participate in their teaching unit's discussion forum are more likely to achieve a higher final mark than those that do not participate. It was also observed that the resulting effect of participation in a teaching unit's online discussion forum was greater for a blended delivery modal than for fully online teaching units. This study affirms how learning analytics data derived from online discussion forums can be proactively applied to enhance teaching and learning practice.
\end{abstract}

Keywords: learning analytics; online discussion forum; academic achievement; social network; social capital; online learning; blended learning; higher education.

Reference to this paper should be made as follows: Carceller, C., Dawson, S. and Lockyer, L. (2013) 'Improving academic outcomes: does participating in online discussion forums payoff?', Int. J. Technology Enhanced Learning, Vol. 5, No. 2, pp.117-132. 
Biographical notes: Charles Carceller has worked in the field of adult education for over 20 years. He holds a Master of Education (Information Technology in Education and Training) and is currently pursuing a Doctor of Philosophy at the University of Wollongong, focusing on the role social capital plays in student's academic achievement in higher education.

Shane Dawson is the Deputy Director of the Learning and Teaching Unit, and Associate Professor of Technology Enhanced Learning at the University of South Australia. His research activities focus on learning analytics and social networks to inform teaching and learning theory and practice. His research has demonstrated the use of learner interaction and network data to provide lead indicators of student sense of community, academic success and course satisfaction. He is a co-founder and executive member of the Society for Learning Analytics research and co-chair of the 2012 Learning Analytics and Knowledge conference in Vancouver, Canada.

Lori Lockyer is the Vincent Fairfax Family Foundation Chair in Teacher Education and Head of the School of Education at Macquarie University in Australia. Her research focuses on learning design, teacher design thinking and practices, and the use of information and communication technology to support learning in K-12 education, professional education, and health education.

\section{Introduction}

There is international consensus that a nation's future economic and social progress will be determined by the reach, quality and performance of that nation's higher education system (Freeman, 2004; Marginson, 2008). This reliance on higher education to develop a globally competitive workforce is well reflected in policy documents calling for increased undergraduate completions in order to position each country more competitively in the globalised economy (OECD, 2012). To meet these goals a variety of strategies including increasing overall student numbers, reducing attrition rates and linking accountability to performance levels have been proposed (OECD, 2012). Many universities have also re-evaluated their teaching models and are taking a more flexible approach to the problem by utilising Information and Communication Technologies (ICT's) and online education to promote greater flexibility in study options and therefore increase student enrolment numbers and completion rates (Johnson et al., 2012).

Over the past decade there has been a substantial shift in the academy surrounding the perception of the quality of online or distance education. The past premise that distance education was inferior to more traditional models was largely based on the lack of opportunity afforded to students to engage in active discussions and peer to peer interactions (Allen and Seaman, 2011; Russell, 2013). However, with the increase in adoption and sophistication of ICTs and the enterprise wide Learning Management System (LMS) there is now a multitude of resources and tools that serve to promote and foster more social learning pedagogies. The effectiveness of teaching models incorporating online learning has been well documented in The US department of education report (Means et al., 2010) on evidence-based practice in online learning. The report demonstrates that on average students undertaking online learning performed better (as determined by grade) than students solely receiving face-to-face instruction. 
For online models of education delivery the integration of synchronous and asynchronous communication tools such as the discussion forum are now seen as essential for promoting student-to-student interactions.

The integration of more socially oriented pedagogical practices, delivered or supplemented through more flexible online modalities is important for improving educational outcomes (Means et al., 2010). The level and type of social relationships a student fosters has a significant impact on educational outcomes. For example Tinto's (1997) study noted that an increase in social interaction with peers can result in decreased attrition rates. Similarly, Richard Light (2001) maintained that the degree of student's participation in small study groups served as a significant predictor of academic achievement. Although Tinto's and Light's research lies in on-campus based models their work demonstrates the importance of network relationships for student learning. In the online learning environment Morris et al. (2005) identified that a significant relationship exists between student time on discussion forum activities and overall academic performance. The use of online discussion forums within a learning environment provides students with greater opportunity to establish and maintain relationships with their peers. Consequently, it becomes necessary to understand the role that participation in online discussion forums plays across different models of instruction.

Learning analytics provides one approach to enable teaching staff to monitor student engagement, progression and support, and identify students at greatest risk of noncompletion. In the context of a social learning pedagogy, learning analytics have been used to identify perceived sense of community (Dawson, 2008), participation and social connections (Fournier et al., 2011) and identify disconnected students and patterns of student-to-student communication (Macfadyen and Dawson, 2010). The data gathered can guide the use of limited resources allowing faculty to customise instruction (Campbell et al., 2007) and improve teaching and learning environments (Ferguson, 2012; Johnson et al., 2012).

The focus for this study was solely on student active participation in the online discussion forum rather than examining the nature or quality of the relationships. Section 2 presents a review of the related works in the areas of learning analytics, social network theory and social capital. Section 3 presents an overview of the methodology of the study. Section 4 details the results of the study and Section 5 presents what, if any, impact online discussion forum activity may have on the student's final mark for fully online and blended teaching units. Section 6 presents the conclusion with implications for teaching and learning practice.

\section{Review of the literature}

\subsection{Learning analytics}

As universities move to increase student numbers there will be increased pressure placed upon infrastructure, support resources and academic workload (e.g., room size, timetabling, technical support, marking, etc.). To address these challenges while supporting greater student enrolments, universities are increasingly relying on ICTs for the delivery of content and to provide more flexibility and opportunities for students to engage with both peers and faculty (Bates, 2000). The use of ICTs is becoming ubiquitous in both online and blended models of higher education (Anderson et al., 2010) 
and is well anticipated to continue as a strategy for universities to meet the flexible learning demands of an increasingly diverse and mobile student cohort while establishing greater enrolment capacity. Learning analytics drawing on the user data evolving from the online learning environment will serve as a valuable tool to support teaching staff in understanding the impact of their learning activities and to proactively support students in their learning endeavours.

Learning analytics describes a method for gathering and analysing learning related data to provide insight and optimise the learning processes (Long and Siemens, 2011). Following the 1st International Conference on Learning Analytics and Knowledge (2011) the formal definition of Learning Analytics was established, as "... the measurement, collection, analysis and reporting of data about learners and their contexts, for purposes of understanding and optimising learning and the environments in which it occurs". The analysis of data from different elements of online learning has identified that there are patterns of engagement that are reflected in academic outcomes. These include patterns that identify perceived sense of community (Dawson, 2008), participation and social connections (Fournier et al., 2011) disconnected students and student-to-student communication (Macfadyen and Dawson, 2010). Learning analytics data and methods can be employed to identify the potential impact of the socialising efforts of active participation in the online discussion forum on the student's final mark. Additionally, this learning and teaching data can be related back to the employed pedagogical model to examine for differences between online and blended modes of delivery. As such, this information can guide teaching and learning practices by providing insight into the role online discussion forums play in both online and blended modes of delivery. In this context, universities can use learning analytics to assist teachers in understanding and monitoring pedagogical practices that are designed to build student social relationships and actively engage students in their learning environment.

\subsection{Social network theory and social capital}

In an educational context, social networks can be used to describe the types of relationships students establish within a learning network. These relationships can be a rich source of informational, instrumental or emotional support and have been shown to heavily influence student academic achievement. The social and academic benefit derived from well-established social ties has been well demonstrated for both offline and online education contexts. For instance, with traditional on-campus education Tinto (1975) and Light (2001) indicate that students who are engaged and socially interactive are more likely to successfully complete their studies than their less interactive peers. In online education, Wozniak (2005) identified that a significant relationship exists between student completion rates from increased peer interaction and support.

Social network theory provides a framework that links individual relationships and social structure to access and control over information (Burt, 1992; Haythornthwaite, 1996). These relationships are a rich source of resources that can be of a material or non-material nature. By introducing social network theory we acknowledge that the individual' relationships (ties) provide significant access to a broader pool of resources that can be drawn upon to facilitate learning and ultimately enhance academic achievement. Lin (2001) argues that the technologies of social media (like those of the online discussion forum) provide an increased and continuous opportunity for individuals to establish and maintain relationships. Through this increased connectivity an individual 
can rapidly extend their network and strengthen and reinforce established relationships. The strength and quantity of established relationships dictate an actor's access to resources, such as information, guidance and support. In the education context these are resources and support structures that can assist a student in their academic endeavours (Sparrowe et al., 2001).

An individual's capacity to access resources is central to the concept of social capital. Lin (2001) defines social capital “....as resources embedded in one's social networks, resources that can be accessed or mobilised through ties in the network" (p.24) and that these "social resources can then generate a return" (Lin, 2008, p.24). Bourdieu (1986) describes social capital as a function of the individual, while Coleman (1990) looks upon the concept of social capital consisting of aspects of both social structure and the actions of individuals within that structure. In moving from a focus on the individual to community, Putnam (1993) relates social capital to attributes of the community with specific and interrelated elements; trust, norms, and networks. Social capital has been defined in many ways and multiple definitions persist, but they all share a common attribute; that is, the source of social capital lies in the relationships established by an individual within a specific social structure. Like other forms of capital, social capital can be described as the resources that an individual has access to directly or indirectly through their social relationships.

These definitions describe social capital as having both an 'individual' and 'collective' component (Lin, 1982; Newton, 1997), bringing together the individual and collective aspects associated with the control and use of resources. Individual aspects of social capital relate to the number of resources that an individual has access to from the pool of resources available within the network. While collective aspects of social capital are seen as a characteristic of the entire group (i.e. resources, functioning social control, system of trust, etc.) and represents the 'collective' resources and attitude as a whole and cannot be created by an individual. These resources are embedded in the network and may be accessed or mobilised by the group or individuals within the group for an expected return. Thus in this context, the level of social capital or the relational connections an individual establishes through their participation in their online discussion forum can ultimately aid their progression through their academic career.

Social capital comes in different forms and is not always interchangeable. The reputation, trust and resulting relationship develops as the level of social engagement increases gradually from superficial to more intimate levels of exchange (Altman and Taylor, 1973). Lin's (2008) network-based theory of social capital recognises these varying patterns of social exchange and delineates them into three layers categorised as: the outer layer, the intermediary layer and the inner most layer. Each layer is differentiated by the level of intensity and reciprocity of the relationships.

The outer layer is characterised by its 'collective' qualities of shared membership and identity (e.g., institution, faculty or class) whether individuals interact or not amongst themselves. When individuals do interact these relationships are characterised by interactions that are general and non-intimate but provide the individuals with a sense of belonging. The intermediary layer is characterised by relationships that share information and resources, while the inner most layer sees the relationships as closer and more intimate and the individuals provide each other with mutual support (i.e. an intimate relationship) and an implied obligation to reciprocate (Lin, 2008). Each layer results in a different type of social capital and provides access to different types of resources that can be of significant value in our lives. 
Thus, social capital refers to the notion of building and maintaining the social relationships that can assist us to achieve our desired goals and objectives (Kennan and Hazleton, 2006). Based on Lin's (2001) view of social capital the achievement of individual goals and objectives is dependent upon two key factors. Firstly, the individual needs to be aware of the collective resources that exist. If an individual is not aware of the resources embedded in the network then they are unlikely to try to access the resources available from the relationships. Secondly, access to the resources is dependent on having sufficient skills and resources to access them. It is this potential of 'social capital' and how students may develop and access the embedded resources of their learning networks through participation in their online discussion forum that holds great potential.

Research into online discussion forums is plentifully and has explored many facets including promoting student engagement (Jahnke, 2010), sense of community (Rovai, 2002; Davies and Graff, 2005; Dawson, 2006), completion rates (Wozniak, 2005) and perceived learning (Picciano, 2002). Online discussion forums are designed to build and maintain students' academic relationships with peers and teachers and while studies (Wang and Tucker, 2001; Davies and Graff, 2005; Morris et al., 2005; Palmer et al., 2008; Dawson, 2010) have looked at discussion forum activity and its impact on marks, there has not been research to identify whether this relationship holds across online and blended modes of delivery and the significance of the comparison between the two. To date there has been minimal research on the relationships between participating in online discussion forums at university and the role participation plays in both online and blended modes of delivery to increase access to social capital.

This study uses learning analytics from the online discussion forum from both online and blended teaching units to examine if participation in the online discussion forum provided access to social capital, which can then be used to access resources to support the student's academic outcomes. This research will help better understand how learning analytics can be employed to analyse social relationships in both online and blended teaching modes and the influence these relationships have on a student's academic outcome. This will provide the opportunity to further develop pedagogical practices to better facilitate and support students in the development of relationships to support their academic endeavours.

\section{Methodology}

\subsection{Research objectives and questions}

The study aimed to determine if an association existed between a student's active participation in the online discussion forum and their final mark for that teaching unit. Specifically, the research addresses the following questions:

- Does a student's active participation in the online discussion forum influence their final mark for that teaching unit?

- Does the teaching unit delivery method influence the impact that participation in the discussion forum has on the teaching unit final mark? 
For the purposes of this study, active participation in the online discussion forum is defined as a student who has at least posted a message or replied to an existing message. Participation was purely based on a post or reply interaction, the content, size of the message, etc. were not examined. Online teaching units are defined as units of study that are delivered fully over the Internet as a substitute to face-to-face instruction. Blended teaching units are those units of study that have combined face-to-face and online instruction. Only those teaching units incorporating an online discussion forum, either as a required or optional component of instruction, were selected for the study. The online discussion forum allows asynchronous group text-based communication and constitutes the main communication tool in the LMS.

\subsection{Context}

The data for the study is drawn from a large Canadian metropolitan university with approximately 45,000 students and in excess of 800 teaching units, adopting an online discussion forum at the time of research. The teaching units were approximately 13 weeks in duration and delivered either as fully online or blended formats. The class sizes varied, with approximately $30 \%$ of the classes with fewer than 15 students, $65 \%$ with 15-79 students per class and 5\% with more than 80 students per class.

The sample for this study came from 300 teaching units in the Faculty of Arts. 20 of these courses were delivered in a fully online modality the remaining 280 units were via a blended model. The study population comprised of students completing the teaching unit (still officially enrolled at the end of the semester) to whom a final mark was awarded (excluding grades of 0 ) resulting in a sample size of $N_{\text {total }}=12,901$ ( 1 st year $=$ 4502 , 2nd year $=3143$, 3rd year $=4094$, 4th year $=1159$ and three post graduate students). Of which 1458 students participated in online teaching units and 11,443 participated in blended teaching units. The data was analysed using the PASW statistical package for the social sciences formally known as SPSS (SPSS Inc., 2009).

\subsection{Data collection and analysis}

The analysis for this study was undertaken to identify if a significant relationship exists between a student's active participation in their online discussion forum and their final academic grade for that teaching unit. This study extracted quantitative data from the universities LMS, which contained details of the student's participation or non-participation in their online discussion forum. The final academic mark, for each student, was collated at the end of the teaching unit for correlations against the forum participation data.

The analysis of this study involves comparing two groups; those that actively participated in their online discussion forum to those that did not. A comparison was made between these two groups and a student's final mark, and how it is related to the teaching units mode of delivery (blended or fully online). Analysis of the distribution of final mark shows the data for both groups to be negatively skewed and have excess kurtosis. This suggests the non-normality of the data distribution, so the Mann-Whitney test was used for the analysis of data.

The authors are aware of the ongoing debate regarding the use of parametric or nonparametric statistics in large sample sizes (Micceri, 1989). While the sample size for this study is considered large (greater than 30) and the central limit theorem could be evoked, 
the authors observed no difference in the findings using both parametric and nonparametric methods. For the purpose of this article only the non-parametric results have been reported.

\section{Results}

The results of this study are presented in three sections. Section one compares the final academic mark of all students who actively participated in their online discussion forum with those students who did not. Section two provides an analysis of student's final marks and the delivery method of the teaching unit (online or blended). Finally, section three compares final mark, delivery method (online or blended) and active participation in the teaching unit online discussion forum.

\subsection{Results: final mark and online participation}

In order to investigate if a difference in final mark existed between those students who actively participated in their online discussion forum and those that did not, a MannWhitney test was conducted. Table 1 presents a summary of the results. The findings indicate that the final mark $(M d n=75.00)$ for those students who actively participated in their teaching unit's online discussion forum was significantly $(p<.001)$ higher than those that did not $(M d n=72.00), U=15880857, p<.001, r=.16$, with an effect size correlation value between small and medium.

Table 1 Summary results of final mark and discussion forum participation

\begin{tabular}{lcc}
\hline & \multicolumn{2}{c}{ Active participation in discussion forum } \\
\cline { 2 - 3 } & No participation & Participation \\
\hline$n-$ No. of students & 8021 & 4880 \\
Median & 72.00 & 75.00 \\
Mean & 69.46 & 73.54 \\
Range & 97 & 97 \\
Minimum & 3 & 3 \\
Maximum & 100 & 100 \\
Effect size measures & \multicolumn{2}{c}{ Cohen's effect size: $d=0.32$} \\
& \multicolumn{2}{c}{ Effect size correlation: $r=0.16$} \\
\hline
\end{tabular}

While the effect size correlation may be interpreted as small to medium effect, this interpretation needs to be put into context. Effect size values are often related to Cohen's (1988) guidelines where values of $d=0.20$ can be considered 'small', $d=0.50$ are medium and those around $d=0.80$ or greater, are considered 'large'. These values are presented by Cohen, as a general 'rule of thumb' in the absence of previous research and should not automatically apply.

Effect size should be interpreted based on the context of the study (Volker, 2006; Hedges and Hedberg, 2007; Hill et al., 2007). Taking into account the nature of the intervention being studied (i.e. use of an online discussion forum), the outcomes being measured and the participants being examined. Hedges and Hedberg (2007) label 
Cohen's conventions as misleading in educational policy context in which effect sizes of Cohen's $d=0.20$ or smaller are often of interest. Hill et al. (2007) demonstrated, across three educational benchmarks (normative expectations for change, policy-relevant gaps and effect size results from similar studies) that an effect size of Cohen's $d=0.10$ is meaningful. The results of this study are considered as both statistically significant and meaningful.

\subsection{Results: final mark and delivery method}

To investigate the existence of variation in final marks between the students who participated in online teaching units and those that participated in blended teaching units a Mann-Whitney $U$ test was conducted. Table 2 presents a summary of the results. The results did not significantly differ and confirms there is no difference in final mark between those students who participated in online teaching units $(M d n=73.00)$ and those that participated in blended teaching units $(M d n=73.00), U=8155013, p=.163, r=.01$.

Table 2 Summary results of final mark and delivery method

\begin{tabular}{lcc}
\hline & \multicolumn{2}{c}{ Delivery method } \\
\cline { 2 - 3 } & Online & Blended \\
\hline$n$ - No. of students & 1458 & 11443 \\
Median & 73.00 & 73.00 \\
Mean & 70.56 & 71.06 \\
Range & 95 & 97 \\
Minimum & 3 & 3 \\
Maximum & 98 & 100 \\
Effect size measures & Cohen 's - effect size: $d=0.04$ \\
& Effect size correlation: $r=0.01$ \\
\hline
\end{tabular}

\subsection{Results: final mark, delivery method and online participation}

To further explore the relationship between the final marks, the modality and forum participation a Mann-Whitney test was again conducted. Table 3 presents a summary of the results of students that actively participated in their teaching unit online discussion forum and those that did not, split by delivery method. The test indicated the results to be statistically significant $(p<.001)$ with the results confirming a positive difference in final mark for those students who actively participated in their teaching unit's online discussion forum than those that did not, irrespective of the delivery method.

While there was no significant difference in final mark for those students that did not participate in their online discussion forum (irrespective of teaching units delivery method), the results for the students that did actively participate in their teaching units online discussion forum showed blended delivered teaching units to have larger Mean and Median differences between those students who actively participated in the forum and those that did not, than those students in fully online teaching units.

In summary, it was observed that student's who actively participation in the online discussion forum (on average) obtained a higher final mark in both online and blended delivery methods than those that did not. In addition, those students who actively 
participated in their online discussion forum in a blended delivered teaching unit (on average) obtained a higher final mark than those students who actively participated in the discussion forum in a totally online teaching unit.

Table 3 Summary results of final mark, delivery method and discussion forum participation

\begin{tabular}{lcccc}
\hline \multirow{2}{*}{ Statistic } & \multicolumn{4}{c}{ Result } \\
\cline { 2 - 5 } & \multicolumn{3}{c}{ Online delivery } & \multicolumn{2}{c}{ Blended delivery } \\
\cline { 2 - 5 } & No participation & Participation & No participation & Participation \\
\hline$n$ - No. of students & 882 & 576 & 7139 & 4304 \\
Median & 72.00 & 74.00 & 72.00 & 76.00 \\
Mean & 69.51 & 72.16 & 69.45 & 73.73 \\
Range & 93 & 95 & 97 & 96 \\
Minimum & 3 & 3 & 3 & 4 \\
Maximum & 96 & 98 & 100 & 100 \\
Effect size measures & Cohen's $d=0.20$ & Cohen's $d=0.34$ \\
& Effect size correlation: $r=0.11$ & Effect size correlation: $r=0.17$ \\
Results & $U=222320, p<.001, r=.11$ & U $r=12335646, p<.001 ; r=.17$ \\
\hline
\end{tabular}

\section{Discussion}

\subsection{Final mark and online participation}

The findings emerging from this study demonstrate that students, who actively participate in their online discussion forum, achieve significantly higher results than those that did not. As Lin (2008) suggests, individuals that 'invest in social relationships' can increase their access to social capital. This increase in social capital can positively influence their ability to access and mobilise informational, instrumental and emotional support. Online discussion forums do provide an opportunity for students to engage with their peers, to establish new or maintain existing relationships. This investment in relationships through the discussion forum can provide students an opportunity to increase their access to social capital. This higher degree of connectivity within the learning network can be leveraged to access resources, and information to support an individual's academic endeavours.

While it has long been recognised that educational attainment and achievement is not just a product of an individual's natural talent. Many factors influence learning, including instruction-related factors, learning-related factors such as age, sex and some biological factors as well as context related factors like social-class, parental education and culture (van Gog et al., 2009). Obviously, many of these factors are not in the direct control of instructors. However, the use of specific ICT's (like those of the online discussion forum) within their learning environment and the adoption of more socially orientated pedagogy are. These aspects can be monitored and constructively manipulated through the use of learning analytics to facilitate student learning (Morris et al., 2005; Dawson, 2010). 


\subsection{Final mark and delivery method}

The results indicate that there was no significant difference in final mark between students who participated in online teaching units and those that participated in blended teaching units. While it is understood that online and blended models of delivery vary in many ways, this result implies that the two groups are the same and that any differences between the online and blended groups did not significantly impact upon a student's assessment. The observed results are aligned to Clark's (1983) theory that the delivery medium has no effect on learning. This is further supported by Russell's (2001) research which also noted that the teaching unit delivery method had no significant difference in student outcomes. However, researchers such as Zhao et al. (2005) have argued that online learning practices in the 21st century are rapidly evolving and will outperform earlier versions of online instruction. With advances in ICTs and their application to education the design and delivery of online education will rapidly evolve. Learning analytics can provide a sound approach for extracting, analysing and interpreting the student trace data in these systems and tools to evaluate the impact of curriculum design and to empower students and teachers in their decisions regarding their learning and teaching practice.

\subsection{Final mark, delivery method and online participation}

The results of this study also indicate that there is a positive difference in final mark for those students who actively participated in their online discussion forum than those that did not (irrespective of the delivery method). However, the results for the blended delivered teaching units on average showed a greater increase in final mark for those students who actively participated in the online discussion forum than the corresponding group from the online teaching units. This difference was also reflected in the effect size correlation values.

According to Boyd and Ellison (2007) students' use social network sites to form and maintain relationships with their offline peers. Subrahmanyam et al. (2008) point out that the overlap between online and offline networks are not perfect, suggesting students selectively choose which relationships to strengthen and reinforce from their offline networks. Students selectively strengthen and reinforce their network to build their pool of social capital. This increase in social capital may be reflected in both the number of relations and the intensity and reciprocity of the relationships (Lin, 1986), providing a competitive advantage through greater access to resources of the social network that is maintained both online and off-line but is available continuously online.

While an online discussion forum can remove some of the barriers associated with face-to-face communication, by being less likely to be dominated by a single person and less bound by conventions (Redmon and Burger, 2004), in doing so elements of the faceto-face experience are lost. Implicit cues, social and cultural context provide additional information in the face-to-face communication process (Olson and Olson, 2000), without which, the interaction and the level of social penetration are weakened. Students may also feel more isolated, disorientated in their online environment or lose motivation (Mazza and Dimitrova, 2007). Resulting in networks established in fully online teaching units to most likely be comprised of relationships of less intensity and reciprocity than those established by students participating in face-to-face teaching units, were the relationships are supplemented by the elements of the face-to-face experience. 
The social networks established by students in fully online teaching units will initially provide a shared membership and identity but may have little social penetration. Described by Lin (2008) as 'outer layer' relationships, these relationships contain a broad range of new resources that may not be available through the student's other networks. However, these resources are not likely to be readily accessible as the relationships in the 'outer layer' are typically weak, and have not yet developed network norms and trust. With time and continued participation the relationships are likely to move to what Lin describes as the 'intermediary layer', providing a greater access to resources. It is at this stage that as Parks and Floyd (1996) point out that personal relationships online between individuals are likely to move offline and provide greater opportunity for the relationships to intensify. As such, the difference in student final grades in the blended model of delivery compared to fully online may be explained by increased access to, and more rapid development of, peer relationships fostered through multi-modalities (offline and online).

Our findings confirm that learning analytics can provide pedagogically valuable information, supporting the understanding from earlier studies (Wang and Tucker, 2001; Morris et al., 2005; Campbell and Oblinger, 2007) that data extracted from LMS's can provide pedagogically valuable information of interaction activity throughout a teaching unit. Contemporary educational theorist emphasises the importance of socially orientated pedagogical practices (Austin, 1993; Tinto, 1997; Light, 2001). These practices can be supported providing students with information that allows then to monitor their level of interaction in their forum and set expectations of interaction against benchmarks that can be developed over time for a particular teaching unit. Teachers can also monitor learner behaviour in their teaching unit's discussion forum. Providing them with a simple and rapid method to identify students who are not sufficiently engaged in discussion (for their mode of delivery) and may be at risk of non-completion. Teachers can then facilitate and guide students to establish and develop relationships with the peers that will assist them in their academic endeavours.

Learning analytics is still in its infancy (Fournier et al., 2011) and teachers adoption of such methods will be dependent on how difficult they perceive it is to use and understand (Rogers, 1995). By providing teachers with simple and easy to understand measures that allow them to evaluate if a discussion forum is contributing to a student's final mark and proving to be an effective tool in their particular context. This information could allow them to make changes to how the discussion forum is structured for the next iteration of the teaching unit and provide a manageable first-step for many educators the use of learning analytics in their teaching unit.

\subsection{Limitations of the study}

This study is limited in not being able to control a large number of variables, which include learner characteristics, teacher involvement, frequency and nature of interactions and instructional method. Brown and Wack (1999) suggest that such a criticism can be made of most research studies in education that look at delivery method as an independent variable.

The sample from the study was taken from a single university in Canada, and as such the results should not be considered generalised across different universities and/or countries. Further investigation is needed to establish if the results can be applied across broader contexts. 
Future research would benefit from analysis of homogeneity of effects within the group of teaching units. If a significant variability in the effect sizes was identified, additional research could help identify other variables that could help explain the different outcomes. Further research is also needed to investigate what types of networks students establish as a result of their online participation and the nature of the resources that are embedded in these networks. Lastly, understanding what encourages student's to participate and mobilise the resources embedded in the social network will help better understand how to engage students to become more active in their teaching unit's online discussion forum.

\section{Conclusion}

With government calls for increased numbers of undergraduates and declining completion rates a concern for universities will be to identify strategies to manage these challenges amidst reduced fiscal resources and constrained by physical infra-structure. While student participation in higher education grows, many universities have also reevaluated their teaching models and have increased the use of ICT's for the delivery of content, not only in distance education but also in campus-based models of instruction. Learning analytics data derived from various ICTs can provide useful information for teaching staff to guide teaching and learning practices and identify and monitor those students at greatest risk of non-completion. This paper begins to provide insight to the relationship that online discussion forums have on academic outcomes in both online and blended modes of delivery.

The study illuminates several implications for teaching and learning practice. Namely students participating in blended teaching units use the online network to selectively develop their existing offline network relationships. In contrast students participating in fully online teaching units (in most cases) first need to establish the relationships before developing the intensity and reciprocity in a relationship that will allow them to establish the type of social capital that will allow them to mobilise the resources in the network. Due to the time constraints associated with teaching practice (timetables, course duration, etc.), students undertaking blended models have greater opportunity to develop stronger network ties that can provide increased social capital to assist them in their academic endeavours.

This study is at an early stage and represents a piece of a larger research project that aims to identify if a relationship exists between a student's academic achievement and their personal social capital. While the paper demonstrates an academic advantage for those students that actively participate in the online discussion forum, it can be concluded that the positive impact on academic achievement can be explained in part through the increased access to resources that the established relational connections affords.

\section{References}

1st International Conference on Learning Analytics and Knowledge (2011) 1st International Conference on Learning Analytics and Knowledge, 27 February-1 March, Banff, Alberta, Canada. Available online at: https://tekri.athabascau.ca/analytics/.

Allen, I.E. and Seaman, J. (2011) Going the Distance: Online Education in the United States, Babson Survey Research Group, Wellesley, MA, USA. 
Altman, I. and Taylor, D. (1973) Social Penetration: The Development of Interpersonal Relationships, Holt, Rinehart \& Winston, New York, NY, USA.

Anderson, T., Poellhuber, B. and McKerlich, R. (2010) 'Self-paced learners meet social software: an exploration of learners' attitudes, expectations and experience', Online Journal of Distance Learning Administration, Vol. 13, No. 3.

Austin, A. (1993) What Matters in College: Four Critical Years Revisited, Jossey-Bass, San Francisco, CA, USA.

Bates, A.W. (2000) Managing Technological Change: Strategies for College and University Leaders, Jossey-Bass, San Francisco, CA, USA.

Bourdieu, P. (1986) 'The forms of capital', in Richardson, J.G. (Ed.): Handbook of Theory and Research for the Sociology of Education, Greenwood Press, pp.46-58.

Boyd, D.M. and Ellison, N.B. (2007) 'Social network sites: definition, history, and scholarship', Journal of Computer-Mediated Communication, Vol. 13, No. 1, pp.210-230.

Brown, G. and Wack, M. (1999) The Difference Frenzy and Matching Buckshot with Buckshot, The Technology Source, May/June.

Burt, R.S. (1992) Structural Holes: The Social Structure of Competition, Harvard University Press, Cambridge, MA, USA.

Campbell, J.P., DeBlois, P.B. and Oblinger, D.G. (2007) 'Academic analytics: a new tool for a new era', EDUCAUSE Review, Vol. 42, No. 4, pp.40-57.

Campbell, J.P. and Oblinger, D.G. (2007) Academic Analytics, EDUCAUSE.

Clark, R.E. (1983) 'Reconsidering research on learning from media', Review of Educational Research, Vol. 53, No. 4, pp.445-459.

Cohen, J. (1988) Statistical Power Analysis for the Behavioural Sciences, 2nd ed., Lawrence Earlbaum Associates, Hillsdale, NJ, USA.

Coleman, J.S. (1990) Foundations of Social Theory, Harvard University Press, Cambridge, MA, USA.

Davies, J. and Graff, M. (2005) 'Performance in e-learning: online participation and student grades', British Journal of Educational Technology, Vol. 36, No. 4, pp.657-663.

Dawson, S. (2006) 'Online forum discussion interaction as an indicator of student community', Australian Journal of Educational Technology, Vol. 22, No. 4, pp.495-510.

Dawson, S. (2008) 'A study of the relationship between student social networks and sense of community', Educational Technology and Society, Vol. 11, No. 3, pp.224-238.

Dawson, S. (2010) 'Seeing' the learning community: an exploration of the development of a resource for monitoring online student networking', British Journal of Educational Technology, Vol. 41, No. 5, pp.736-752.

Ferguson, R. (2012) 'Learning analyitcs: drivers, developments and challenges', International Journal of Technology Enhanced Learning, Vol. 4, Nos. 5/6, pp.304-317.

Fournier, H., Kop, R. and Sitlia, H. (2011) 'The value of learning analytics to networked learning on a personal learning environment', Paper presented at the International Conference on Learning Analytics and Knowledge, 27 February-1 March, Banff, Alberta, Canada, pp.104-109.

Freeman, C. (2004) 'Income inequality in changing techno-economic paradigms', in Reinert, S. (Ed.): Globalization, Economic Development and Inequality, Edward Elgar, Cheltenham, UK.

Haythornthwaite, C. (1996) 'Social network analysis: an approach and technique for the study of information exchange', Library and Information Exchange Research, Vol. 18, No. 4, pp.323-342.

Hedges, L.V. and Hedberg, E.C. (2007) 'Intraclass correlation values for planning grouprandomized trials in education', Educational Evaluation and Policy Analysis, Vol. 29, No. 1, pp.60-87. 
Hill, C.J., Howard, B.S., Black, A.R. and Lipsey, M.W. (2007) Empirical Benchmarks for Interpreting Effect Size in Research, MDRC Working Papers on Research Methodology: MDRC.

Jahnke, J. (2010) 'Student perceptions of the impact of online discussion forum participation on learning outcomes', Journal of Learning Design, Vol. 3, No. 2, pp.27-34.

Johnson, L., Adams, S. and Cummins, M. (2012) The NMC Horizon Report, 2012 Higher Education Edition, Austin, Texas.

Kennan, W.R. and Hazleton, V. (2006) 'Internal public relations, social capital and the role of effective organizational communication', in Botan, C.H. (Ed.): Public Relations Theory II, Lawrence Erlbaum Associates, Mahwah, NJ, USA, pp.311-338.

Light, R.J. (2001) Making the Most of College: Students Speak Their Minds, Harvard University Press, Cambridge, MA, USA.

Lin, N. (1982) 'Social resources and instrumental action', in Marsden, P.V. and Lin, N. (Eds): Social Structures and Network Analysis, Sage Publications, Beverley Hills, CA, USA.

Lin, N. (1986) 'Conceptualizing social support', in Lin, N., Dean, A. and Ensel, W.M. (Eds): Social Support, Life Events, and Depression, Academic, Orlando, FL, USA, pp.17-30.

Lin, N. (2001) Social Capital: A Theory of Social Structure and Action, Cambridge University Press, New York, NY, USA.

Lin, N. (2008) 'A network theory of social capital', in Castiglione, D., van Deth, J.W. and Wolleb, G. (Eds): The Handbook of Social Capital, Oxford University Press, New York, NY, USA, pp.50-69.

Long, D.P. and Siemens, G. (2011) 'Penetrating the fog: analytics in learning and education', EDUCAUSE Review, Vol. 46, No. 5, pp.30-40.

Macfadyen, L.P. and Dawson, S. (2010) 'Mining LMS data to develop an "early warning system" for educators: a proof of concept', Computers \& Education, Vol. 54, No. 2, pp.588-599.

Marginson, S. (2008) The Global Position of Australian Higher Education to 2020, Centre for the Study of Higher Education (CSHE), University of Melbourne, Melbourne, Australia.

Mazza, R. and Dimitrova, V. (2007) 'Coursevis a graphical student monitoring tool for supporting instructors in webbased distance courses', International Journal of Human-Computer Studies, Vol. 65, No. 2, pp.125-139.

Means, B., Toyama, Y., Murphy, R., Bakia, M. and Jones, K. (2010) Evaluation of Evidence-Based Practices in Online Learning: A Meta-Analysis and Review of Online Learning Studies (Revised).

Micceri, T. (1989) 'The unicorn, the normal curve, and other improbable creatures', Psychological Bulletin, Vol. 105, No. 1, pp.156-166.

Morris, L.V., Finnegan, C. and Wu, S. (2005) 'Tracking student behavior, persistence, and achievement in online courses', The Internet and Higher Education, Vol. 8, No. 3, pp.221-231.

Newton, K. (1997) 'Social capital and democracy', American Behavioural Scientist, Vol. 40, No. 5, pp.575-586.

OECD (2012) Education at a Glance 2012: OECD Indicators, OECD Publishing.

Olson, G.M. and Olson, J.S. (2000) 'Distance matters', Human-Computer Interaction, Vol. 15, Nos. 2/3, pp.139-178.

Palmer, S., Holt, D. and Bray, S. (2008) 'Does the discussion help? The impact of a formally assessed online discussion on final results', British Journal of Educational Technology, Vol. 39, No. 5, pp.847-858.

Parks, M.R. and Floyd, K. (1996) 'Making friends in cyberspace', Journal of Communications, Vol. 46, No. 1, pp.80-97.

Picciano, A.G. (2002) 'Beyond student perceptions: issues of interaction, presence, and performance in an online course', Journal of Asynchronous Learning Networks, Vol. 6, No. 1. 
Putnam, R.D. (1993) 'The prosperous community: social capital and public life', The American Prospect, Vol. 4, No. 13, pp.35-42.

Redmon, R. and Burger, M. (2004) 'WebCT discussion forums: asymchronous group reflection of the student teaching experience', Curriculum and Teaching Dialogue, Vol. 6, No. 2, pp.157-166.

Rogers, E.M. (1995) Diffusion of Innovations, 4th ed., Free Press, New York, NY, USA.

Rovai, A.P. (2002) 'Sense of community, perceived cognitive learning, and persistence in asynchronous learning networks', The Internet and Higher Education, Vol. 5, No. 4, pp.319-332.

Russell, T.L. (2001) The No Significant Difference Phenomenon: A Comparitive Research Annotated Bibliography on Technology for Distance Education, IDECC, Montgomery, Alabama.

Russell, T.L. (2013) The No Significant Difference Phenomenon. Available online at: http://www. nosignificantdifference.org/ (accessed on 3 January 2013).

Sparrowe, R.T., Liden, R.C., Wayne, S.J. and Kraimer, M.L. (2001) 'Social networks and the performance of individuals and groups', The Academy of Management Journal, Vol. 44, No. 2, pp.316-325.

SPSS Inc. (2009) PASW Statistics (Version 18.0), SPSS Inc., Chicago, IL, USA.

Subrahmanyam, K., Reich, S.M., Waechter, N. and Espinoza, G. (2008) 'Online and offline networks: use of social networking sites by emerging adults', Journal of Applied Developmental Psychology, Vol. 29, pp.420-433.

Tinto, V. (1975) 'Dropout from higher education: a theoreticalsynthesis of recent research', Review of Educational Research, Vol. 45, No. 1, pp.89-125.

Tinto, V. (1997) 'Classrooms as communities: exploring the educational character of student persistence', Journal of Higher Education, Vol. 68, No. 6, pp.599-623.

van Gog, T., van Hell, J.G., Jenks, K., Jolles, J., de Jong, T., Manlove, S., van Leeuwen, T., van Merrienboer, J. and Boschloo, A. (2009). Explorations in Learning and the Brain: A Quick Scan of the Potential of Neuroscience for Education, Springer.

Volker, M.A. (2006) 'Reporting effect size estimates in school psychology research', Psychology in the Schools, Vol. 43, No. 6, pp.653-672.

Wang, A.Y. and Tucker, T.L. (2001) 'A discourse analysis of online classroom chats: predictors of cyber-student performance', Teaching of Psychology, Vol. 28, No. 3, pp.222-226.

Wozniak, H. (2005) Online Discussions: Improving the Quality of the Student Experience. Available online at: http://citeseerx.ist.psu.edu/viewdoc/download?doi=10.1.1.83.7293\& rep=rep1\&type $=$ pdf (accessed on 8 December 2012).

Zhao, Y., Lei, J., Yan, B., Lai, C. and Tan, H.S. (2005) 'What makes the difference? A practical analysis of research on the effectiveness of distance education', Teachers College Record, Vol. 107, No. 8, pp.1836-1884. 